step-ladder fashion, spasmodic movements of the muscles of the head and face set in, of sudden onset and sudden disappearance. These spasmodic movements gradually spread over the whole body and extremities, occurring several times during the day and also during sleep at nights. They were always bilateral.

Major Lee, the Civil Surgeon, on consultation, thought that the movements were choreiform in type. Unlike true chorea, however, if the muscles were forcibly held, e.g., those of the extremities, the spasmodic movements at once ceased, only to recur when pressure was discontinued. The spasms would continue for 15 to 30 minutes, but were unattended by any pain, although they left the patient exhausted.

There was extreme constipation at the time, and the urine was very scanty, although the bladder. was full. The temperature subsided by the end of the fourth week, but the choreiform movements continued after the fever had subsided. It is to be noted that the father of the child gave a history of rheumatism; she herself was fairly well nourished, and had never previously had such attacks. The menstrual flow had not yet appeared.

Treatment. The constipation and the distended bladder were relieved by mechanical means; and calcium lactate, 15 grs. with parathyroid extract, gr. 1, was given thrice daily. Lemon whey and fresh fruit juices were given. In the course of a couple of weeks the symptoms subsided, and the child is now in good health.

Remarks. Chorea is known to follow acute infections and intoxications, and is, of course, well known as a complication of rheumatic fever in childhood. The writer, however, has never seen it as a complication of typhoid fever. The severe constipation and scanty urine were marked features of the case, and may have contributed to the onset of the chorea. The choreiform movements having suggested a deficiency in calcium, calcium was administered both orally as calcium lactate, and also in the diet prescribed; parathyroid extract being added in order to assist the calcium metabolism. Vines has shewn that calcium salts are present in the blood in two forms; combined with the plasma, where they take part in blood coagulation; and free, in an ionised form. Biochemists have also shewn that excess of calcium depresses, whilst deficit of calcium increases nervous irritability, magnesium taking the place of the calcium in the latter condition. Harrower has shewn that the activity of the parathyroids governs the calcium metabolism of the body. Hence, in the present case, the indications appeared to be to give calcium salts both orally and in the diet, and to add parathyroid extract.
AN UNUSUAL EFFECT IOF MALARIA UPON THE HEAR'T.

\author{
By KRISHAN LAL KHERA, м.в., в.S., \\ Jaramwala, Lyallpur, Punjab.
}

S. M., a Hindu male aged 35 , consulted me on the 19th December, 1924, complaining of fever coming on daily at 4 p.m. with rigor and passing off at 11 p.m., and of one week's duration. On examination I found the radial pulse on both sides practically imperceptible, with only an occasional beat perceptible. The spleen and liver were both enlarged. On auscultation, the heart was beating exactly as does the fotal heart, with no regular pauses between the sounds, which were weak and scarcely distinguishable from one another. On percussion there was no abnormality in the outline of the heart. With all this, the patient was walking about, complaining of no cardiac symptoms except slight palpitation on walking. The heart was beating at the rate of 210 per minute, and the temperature at the time of examination (9 a.m.) was $98^{\circ} \mathrm{F}$.

I put the patient on to quinine, 10 grs. t.d.s. in solution, and on the following morning found that the radial pulse had returned, but was very weak, and at a rate of 90 per minute. He had not had the usual rigor on the preceding day.

On continuing the quinine treatment his pulse rate came down to 82 on the 21 st, and the heart sounds were regular and clear, and there was no fever. On the 22nd the pulse rate was 74 , with normal heart sounds.

The case illustrates the profound influence of malaria on the cardiac mechanism.

\section{A CASE OF TRIPLETS.}

By BINODE KRISHNA BANERJI, M.в., Coomar Charitable Dispensary, Chanditala P. O.,
Hughli.

I was called in to see a multipara, aged about 22 , in her fourth confinement, with a history of previous miscarriage due to cholera. She had lost her husband a month previously, and had had to travel in a railway carriage with slight pains just before the date due for delivery. On my arrival the family doctor informed me that she had had a fit a few hours previously and had been given gr. $\frac{1}{2}$ of morphia hypodermically. The dai in charge stated that the os was dilated to one finger width. The patient was exhansted and restless.

On abdominal palpation, a case of twins was diagnosed, and on vaginal examination the os was found to be dilated, with the presenting head low down. Forceps delivery was resorted to, but the child was born in blue asphyxia, probably due to pressure on the cord by the head of the second child. The cord was at 
once cut between two artery forceps, and artificial respiration resorted to.

After a second examination, a second child was delivered by forceps; and later a third child " in caul" on pressure on the fundus. A hot douche was given, and an injection of ergotine citrate, and a post-partum mixture prescribed. The placenta was a large one; all three children were of the same sex (female) and equally developed. They all lived for only some 48 hours; the mother, however, made an uneventful recovery.

\section{THE DOSAGE OF ANTI-TETANIC SERUM.}

\section{By M. A. KRISHNA IYER, L.M.P.,} Natcharkoil, Tanjore District.

Is the October 1924 issue of the Indian Medical Gazette, Dr. Nagendra Nath Ghosh reported the treatment of a case of puerperal tetanus with anti-tetanic serum in doses much smaller than those generally recommended or advocated in the text books. Shortly after the publication of his case, I had occasion to deal with two cases of tetanus, one after the other, for which I adopted the same procedure of treating them with small doses of antitetanic serum with success. Though there is nothing unusual in these cases, it may be of interest to note that smaller doses of serum than the single massive doses of 15,000 to 20,000 units usually advocated can often be employed with success, and with considerable saving of expenditure.

Case 1. On the 9th October, 1924, I was called to see a woman, aged 30 , in a neighbouring village, on the eighth day of her illness. The infection with tetanus had apparently been contracted by the genital route as the result of a miscarriage in the fourth month of pregnancy, some 25 days previously. When I saw her, lock-jaw was complete, and the spasms of the whole body so numerous that I witnessed about 50 attacks during the hour which I spent in attendance on her that day. The temperature was $101.5^{\circ} \mathrm{F}$., and risus sardónicus was well marked.

Two hypodermic injections of the serum, each of 1,500 units were given that day; and repeated doses each of 1,500 units on the 10 th, 11 th and 12 th October. The number of convulsions was now reduced, but her condition was otherwise unchanged. The same dose of 1.500 units was again repeated on the 14 th, 16 th, 17th, 18th and 19th October, the doses being given intravenously.

On the 19th, her condition was markedly improved; two further similar intravenous injections were given on the 21 st and 23rd, after which the spasms ceased to appear; she could sit up and take food, and even walk with assistance.
From the beginning the usual bromide and chloral mixture was given. The injections were now stopped, and convalescence was uneventful.

Case 2. This was in a boy aged 9 year: whom I first saw on the third day of illness. He had been vaccinated some three weeks previously, and, as I could find no other lesion which could have been responsible for the tetanus, I am inclined to incriminate the vaccination. The symptoms and signs were typical of tetanus, and although the number of spasms was less frequent than in the first case, the opisthotonus posture assumed during each spasm was very marked and continued for some twenty minutes at a time, the boy screaming out during each attack.

I first saw him on the 2nd January, 1925, when the tetanus was of three days' duration, and gave 750 units hypodermically that day. From the 3rd to the 9th January, a daily dose of 750 units was given intravenously. By this time the boy's condition was much improved; he could open his mouth; the spasms were few and of short duration; he could sit up and slept well. Two more intravenous injections, each of 750 units, were given on the 11th and 13th. By the 15th the patient could walk with help, and could take his normal food. In this case also the usual bromide and chloral mixture was given.

As pointed oat by Dr. N. N. Ghosh, repeated administration of small doses of anti-tetanic serum may be just as efficacious as the administration of one or two heroic doses. There were no untoward symptoms of any kind in these two cases as the result of giving small doses in place of large; whilst the cost of anti-tetanic serum is so high that large single doses prove very expensive. The serum used in these two cases was that of Messrs. Parke, Davis \& Co.

\section{A TUMOUR OF THE ABDOMINAL WALL.}

By R. K. BASU, Assistant Surgeon, Balasore.

M. B., a Mahomedan male, aged about 32 was admitted to the Balasore Hospital on the 27th August, 1924.

Clinical signs on admission.-On inspection a distinct swelling is visible in the middle of abdomen, more in the lower part than in the upper; on palpation, the swelling is distinctly hard to the touch; its area is 6 in. $\times 6$ in; the skin is movable over it and it is also distinctly tender; no redness of the skin nor any œdema in it. The feeling of the swelling is like that of a solid abdominal tumour; its duration is a fortnight before admission and it is in the same condition as at first; there is no fluctuation in the swelling. 